\title{
ANÁLISE DA ELASTICIDADE DA GASOLINA NO SUDESTE DO BRASIL NO PERÍODO DE 2012 A 2019
}

Evra Albuquerque - Universidade Cândido Mendes (evraalbuquerque@yahoo.com.br)

Luiz Fernando Matos - Universidade Cândido Mendes (lfcmatos@globo.com)

Márcia Souza - Universidade Cândido Mendes (mvvieirasouza@gmail.com)

Daiane Rodrigues dos Santos - Universidade Cândido Mendes (daianesantoseco@gmail.com)

\section{Resumo}

A gasolina é o mais importante dos combustíveis derivados de petróleo do mundo, ela é utilizada na maior parte dos veículos de pequeno porte e, no Brasil, em especial no Sudeste região que possui maior PIB e maior frota de veículos do país esta realidade não é diferente. Responsável por 37\% do mercado de combustíveis no país (dados ANP - 2019) e com o preço fortemente influenciado pelo valor do barril de petróleo e da desvalorização do dólar na comparação com o real, alterações no preço deste combustível afetam diretamente o bolso das famílias. Desde 2016, a Petrobras, principal produtora de gasolina no país passou a atrelar o preço dos derivados, incluindo a gasolina, àqueles praticados no mercado internacional. A mudança na política de preços da Petrobras modificou a estrutura de preços do mercado de combustíveis no país, pois apesar de não ser monopólio, a empresa detém a maior parcela do mercado e seus preços acabam por definir os preços do mercado brasileiro. Apesar do crescimento cada vez maior do mercado de biocombustíveis e, consequentemente, a ampliação das possibilidades de fontes de energia, a gasolina ainda é um bem de grande relevância. Com a entrada dos veículos flexfuel em 2005 a elasticidade preço-demanda da gasolina foi modificada, apesar de possuir uma baixa elasticidade, já é possível perceber uma mudança no comportamento do consumidor em relação à demanda, que antes era inelástica.

Palavras chave: Elasticidade, Demanda, Gasolina, Biocombustível. 


\section{Introdução}

\subsection{O Petróleo como principal matriz energética}

A matriz energética de um país possui forte influência no seu crescimento econômico e muitas vezes, determina a sua forma de industrialização. Economias altamente dependentes de petróleo sofrem com impactos ocasionados por crises e ficam à mercê dos grandes produtores. Investir em energia renovável ainda é algo caro comparado com combustíveis fósseis. O estímulo para novos investimentos em fontes alternativas de energia passa por oferta de recursos e de crédito e pela definição de um marco legal compatível com as demandas de um novo paradigma tecnológico capaz de sustentar a ampliação do modelo nacional de produção de energia (UCZAI, 2012).

Há um consenso que a mudança na matriz energética mundial é inevitável, principalmente quando se trata do consumo de combustíveis fósseis para o transporte automotivo, tanto pelo esgotamento das reservas petrolíferas como pela agressão ao meio ambiente provocado pela emissão de gases, a busca por energia renovável se faz indispensável (ORELLANO et al 2013).

Segundo dados da EIA - U.S. Energy Information Administration (2017), o Brasil é o nono maior produtor de petróleo do mundo. Apesar de possuir autossuficiência no que tange à quantidade de petróleo produzida, o país não é autossuficiente na produção de derivados, sendo necessário importar gasolina para consumo. Esta é mais uma das justificativas da necessidade de determinação de preços pelo mercado internacional. Por diversos anos, a Petrobras assumiu os custos de preços de derivados determinados por estratégia política, vendendo combustível abaixo do custo de importação.

Com respeito à competição no mercado, Santos (2012) destaca que a gasolina ainda é o principal combustível, embora a concorrência com o etanol e o GNV tenha aumentado. Ainda neste contexto, o autor enfatiza que, no curto prazo, o diesel não é um concorrente potencial da gasolina, dada a composição da frota de veículos no Brasil, sendo usado somente por veículos de grande porte.

De acordo com Sant Anna e Bastos (2014), a partir da década de 70, com as mudanças estruturais ocorridas no Brasil o petróleo passou a ser a principal fonte de combustível. Em 2006, a demanda por combustíveis, acompanhando o crescimento econômico do país, sofreu uma forte aceleração e, apesar da crise internacional iniciada em 2008, o consumo de gasolina no Brasil continuou crescendo a taxas superiores às do PIB. Diante do exposto, foi gerado um 
déficit na balança comercial de petróleo e derivados, devido ao aumento significativo das importações para atender a demanda interna de combustível, mais precisamente de gasolina.

Dados do DENATRAN revelam que o Brasil tinha, em junho de 2019, uma frota de 102.666.444 veículos, sendo a maior parte automóveis (55.627.966). O Sudeste possui a maior frota (49.805.810, sendo 30.350.700 automóveis). SP possui a maior frota no Sudeste (29.558.713, sendo 18.494.928 automóveis), sendo seguido por MG (11.445.311, sendo 6.310.860 automóveis), o RJ possui a terceira frota da região (6.831.646, sendo 4.572.487 automóveis) e, por último está o ES (1.970.140, sendo 972.425 automóveis).

Em 2018 o consumo de combustíveis ficou estagnado, os altos preços praticados, situando-se acima dos preços do mercado internacional, impactaram neste resultado. Entretanto, apesar dos valores gerais não terem se alterado, houve um aumento no consumo de etanol hidratado. Os altos preços da gasolina contribuíram para a migração de demanda entre os tipos de combustível. A forte crise econômica enfrentada pelo país nos últimos anos também é considerada um fator relevante de impacto no consumo de combustíveis no país.

O presente trabalho tem como objetivo apresentar um estudo da variação de preço e a demanda por gasolina na região Sudeste, elasticidade-preço cruzada com o etanol e elasticidade-renda da gasolina, entre 2012 e junho de 2019.

\section{A volatilidade do preço do petróleo e suas consequências}

O primeiro choque do petróleo aconteceu em 1973, quando Israel ocupou os territórios palestinos, utilizando o petróleo como força política com objetivo que opinião pública ficasse contra a Israel. Neste contexto, os produtores organizados na OPEP, em forma de cartel, decidiram elevar o preço do barril de petróleo de US\$2,90 para US\$11,65. O segundo choque teve início no Irã, em 1979, com a Revolução Islâmica e se estendeu até 1981. Neste período o barril do petróleo teve um aumento de mais de $1.000 \%$, mantendo o preço elevado até meados da década de 80.

Uma análise do século XXI revela que o preço desta commodity tem um comportamento bastante instável. Ao final de 2008 (Buainain Et al., 2015), motivada pela crise econômica global, houve uma queda no preço do barril, porém por um curto período. Em 2011 já estava em um patamar de US\$100,00. A oscilação mais recente e significativa aconteceu em fevereiro de 2014 quando o preço do barril alcançou US\$ 110,00, porém em dezembro do mesmo ano foi comercializado por US\$62,00. 
Gráfico 1 - Preços médios anuais no mercado spot dos petróleos tipos Brent e WTI

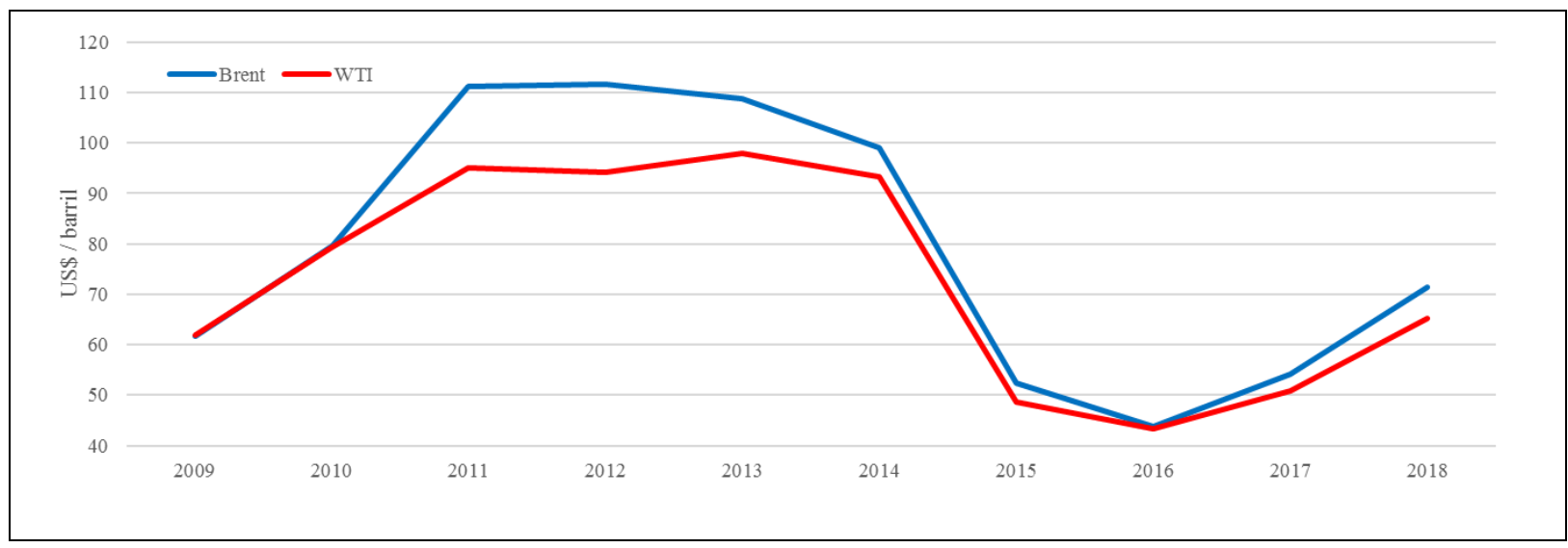

Fonte: BP Statistical Review of World Energy (2019)

\subsection{Efeitos da volatilidade do preço do petróleo no Brasil e a criação do Programa Nacional do Álcool}

O petróleo já era a principal fonte energética do Brasil em 1973, quando ocorrera o primeiro choque do petróleo. Reflexo do processo intensificado de industrialização que o país vinha implantando e alavancando um grau de dependência de petróleo, na época, em torno de $77 \%$, o aumento ocorrido em cerca de $400 \%$ do preço do barril foi responsável por um forte impacto na balança comercial. Com o processo de crescimento, devido às mudanças estruturais vividas no país, o consumo por petróleo cresceu em 6,4\% entre 1974 e 1979. Segundo Pinto Jr. (1989), tal fato pode ser explicado pela inelasticidade-preço da demanda por petróleo no curto prazo e pela inexistência de produto substituto.

A dependência da importação de petróleo foi aflorada pelos choques de 1973 e 1979, que desenvolveu a necessidade de produzir petróleo em território nacional, bem como de pesquisar produtos substitutos. Neste cenário, a Petrobras aumentou a oferta de petróleo e surgiu o PNA, que tinha como primeiro objetivo diminuir o volume de importação de petróleo. Na segunda fase do PNA - 1979 a 2005 - houve a produção de 5,6 milhões de veículos movidos somente a álcool hidratado. Dois fatos impulsionaram a produção do álcool pela indústria canavieira: o baixo preço pago pelo açúcar no mercado internacional e as políticas de preços estabelecidas para estimular o consumidor a utilizar o novo combustível.

A segunda fase do PNA ficou conhecida como Proálcool e entre as principais medidas para incentivar a aquisição do carro a álcool relaciona-se: 
- Em 1980 o preço do álcool foi fixado em 65\% do preço da gasolina, caindo para 59\% em 1982 o que justificava um ganho real para o consumidor;

- Incentivo fiscal devido à redução da carga tributária para a aquisição de veículos novos, movidos a álcool e, uma elevação de 5\% dos tributos para aquisição de carros à gasolina;

- Redução de 3\% do valor do IPVA dos carros a álcool em comparação com carros movidos à gasolina.

Em 1986, o contrachoque do petróleo tornou inviável os investimentos em novas fontes de matriz energéticas para substituição do petróleo. No Brasil, o reflexo dessa queda brutal nos preços do petróleo internacional foi simultâneo a um período de redução de recursos públicos destinados a subsidiar programas de estímulos a fontes de energias alternativas. Enquanto as reduções de investimentos nos projetos de produção de energia não oriundas do petróleo aconteciam, a venda de carros a álcool chegava a 75\% dos carros produzidos, ocasionando um desequilíbrio entre a oferta e a demanda no mercado interno. Os baixos preços recebidos pelos produtores de álcool aliado à queda drástica do preço do petróleo internacional foram fatores que impediram o aumento da produção interna de álcool. Em contrapartida, a população continuava recebendo incentivos para o consumo, levando a uma crise de abastecimento, entre os anos de 1989 e 1990, que acabou afetando a credibilidade do Proálcool. Estes fatores culminaram, na década de 90, em uma queda no número de veículos movidos a álcool e, como consequência, a um decréscimo da demanda por este combustível.

Gráfico 2 - Produção de álcool anidro e hidratado $\left(10^{6} \mathrm{~m}^{3}\right)$

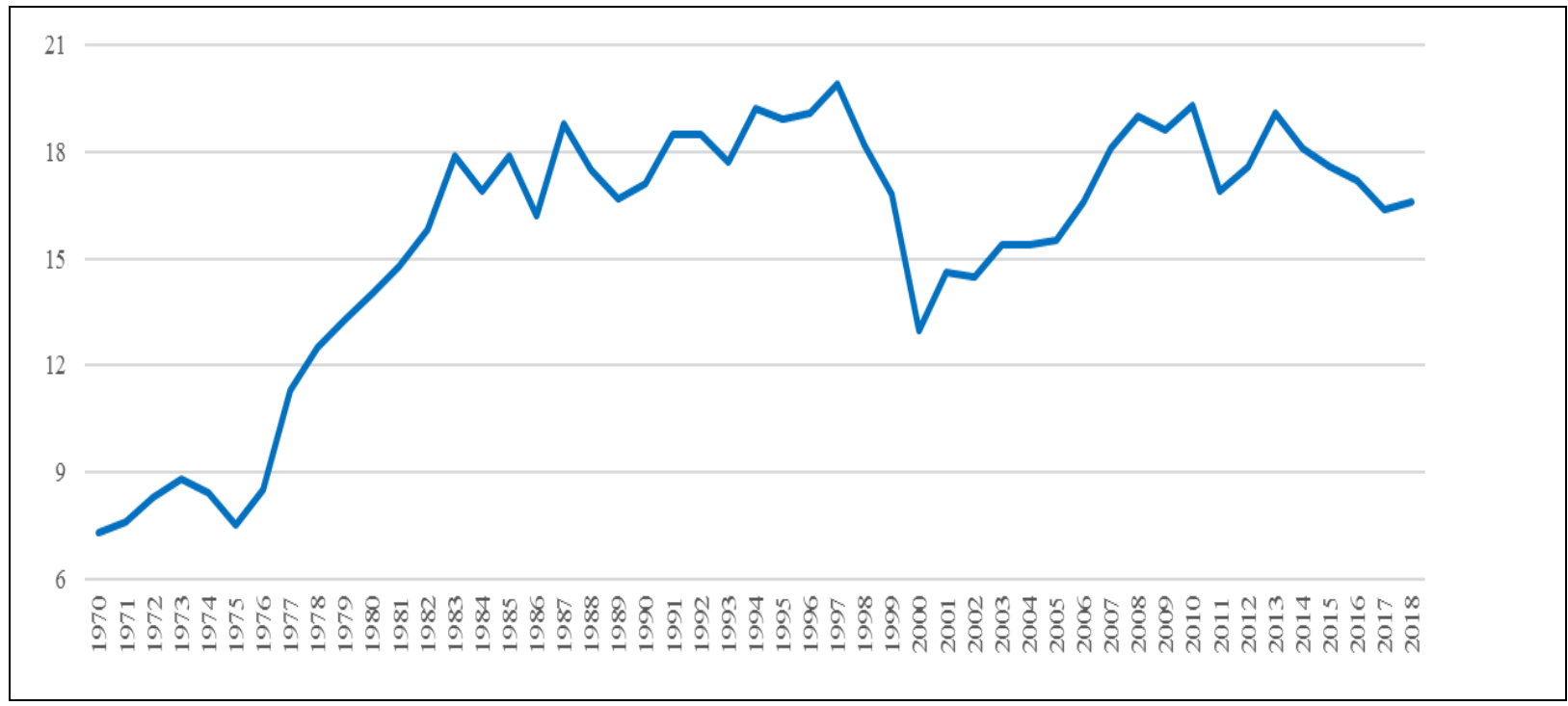

Fonte: Adaptado de MME - Balanço Energético (2019) 
Trazendo para atualidade, estudos recentes buscam explicar a relação entre o álcool e a gasolina, no intuito de encontrar o grau de substituição entre eles. Desde a década de 1970, no primeiro choque do petróleo, o Brasil já havia começado a desenvolver uma relação entre o consumo da gasolina e do álcool (Melo e Sampaio, 2014).

Vale ressaltar que "etanol” se refere ao "álcool”. Essa mudança de nomenclatura ocorre em função de uma resolução da Agência Nacional de Petróleo (ANP) de setembro/2010.

Gráfico 3 - Evolução da venda de gasolina e etanol no Sudeste

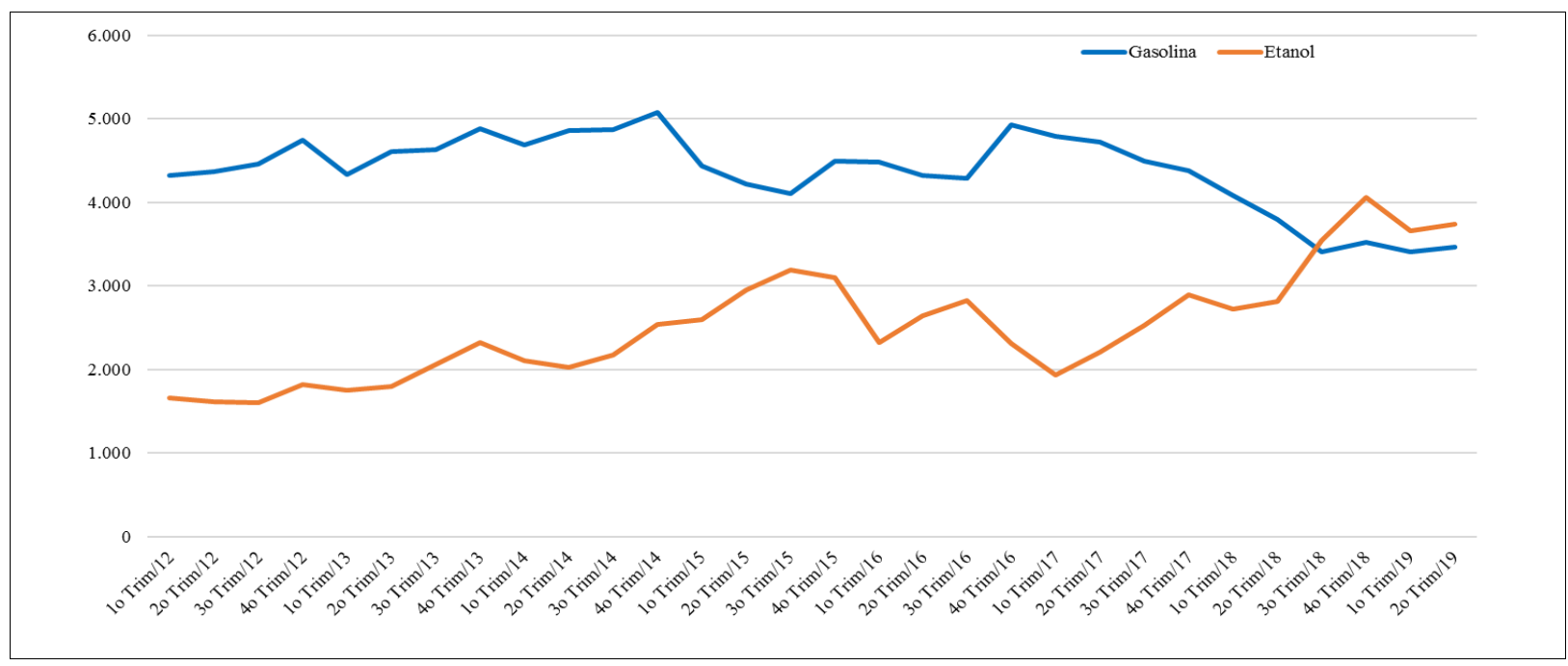

Fonte: Agência Nacional de Petróleo (2019)

Gráfico 4 - Evolução do preço da gasolina e etanol no Brasil (em R \$/litro)

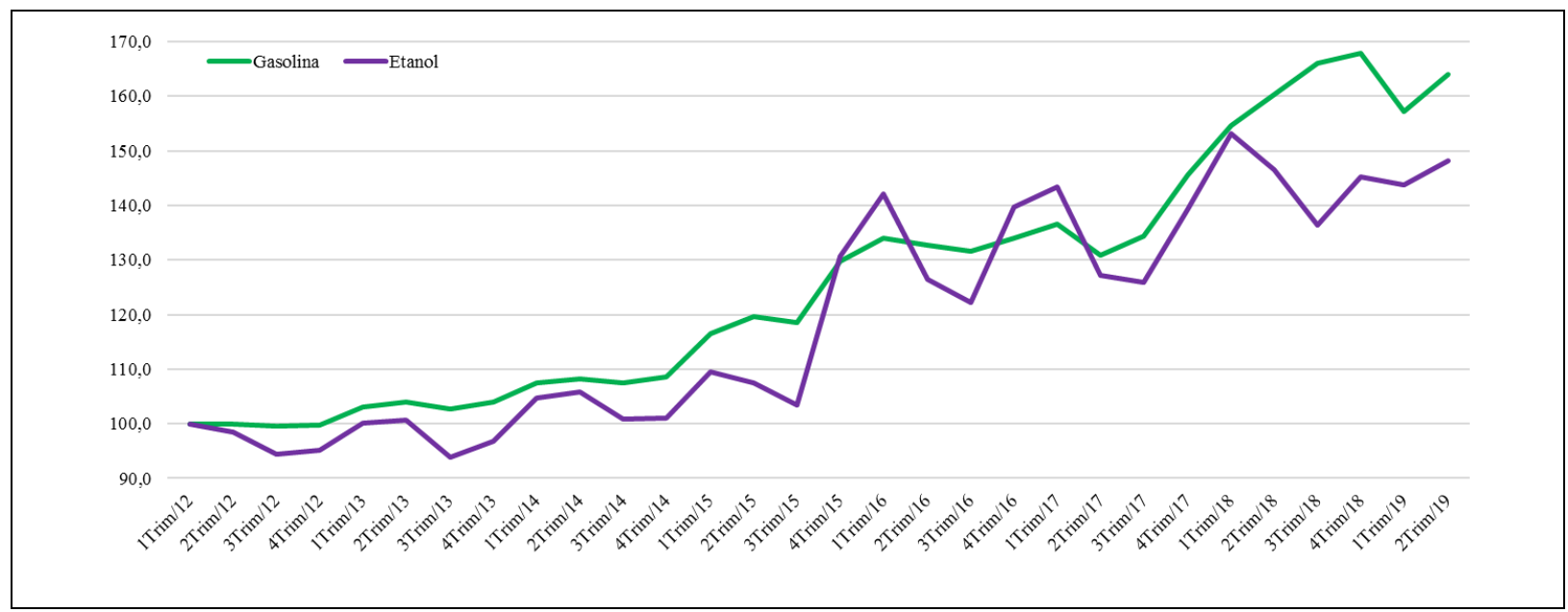

Fonte: Agência Nacional de Petróleo (2019) 


\section{Elasticidade: uma análise teórica}

O conhecimento da elasticidade deve fazer parte do processo de gestão das empresas. A análise da elasticidade pode ser vista das seguintes formas: (i) Elasticidade preço da demanda; (ii) Elasticidade cruzada; e (iii) Elasticidade renda.

\subsection{Elasticidade preço da demanda}

A elasticidade preço demanda é a variação proporcional em quantidade comprada dividida pela variação proporcional do preço. Em outras palavras, mostra quanto varia a quantidade demandada se o preço mudar em 1. Segundo Vasconcellos e Garcia (2014, p. 51) trata-se algo relevante e exemplifica de forma prática como pode ser usado:

O conceito de elasticidade representa uma informação bastante útil tanto para as empresas como para a administração pública. Nas empresas, a previsão de vendas é de extrema importância, pois permite uma reação dos consumidores em face das alterações nos preços da empresa, dos concorrentes e em seus salários. (Vasconcellos e Garcia, p. 51, 2014)

A elasticidade é determinada por: (a) Preço de venda do produto; (b) Preço de venda de outros produtos; (c) Renda do consumidor; (d) Gostos ou preferências; (e) Número de bens relacionados.

Pyndyck e Rubinfeld (2010) descrevem que a elasticidade-preço demanda é descrita por variação percentual, onde a variação na quantidade vendida é dada em relação à variação do seu preço. A elasticidade é negativa, sendo que uma elevação no preço resultará em uma redução na quantidade demandada. Saber a elasticidade-preço demanda é fundamental para qualquer gestão, não só do estoque, mas também dos seus preços de venda de qualquer empresa. Saber o impacto que o aumento ou redução de preços gera na demanda dos seus consumidores e, por consequência, no faturamento.

Assim, a fórmula da elasticidade é:

$$
e=\frac{\Delta Q x / Q x}{\Delta P x / P x}
$$

Em função do resultado da equação acima podemos ter 3 situações: 
Quadro 1 - Classificação da elasticidade

\begin{tabular}{|l|l|}
\hline Classificação da Elasticidade & \multicolumn{1}{c|}{ Definição } \\
\hline Elástica & $\begin{array}{l}\text { A variação da quantidade demanda é superior à } \\
\text { variação do preço. }|\Delta \mathrm{Q}|>|\Delta \mathrm{P}|\end{array}$ \\
\hline Inelástica & $\begin{array}{l}\text { A variação da quantidade demanda é inferior à } \\
\text { variação do preço. }|\Delta \mathrm{Q}|<|\Delta \mathrm{P}|\end{array}$ \\
\hline Elasticidade Unitária & $\begin{array}{l}\text { A variação da quantidade demanda é igual à } \\
\text { variação do preço. }|\Delta \mathrm{Q}|=|\Delta \mathrm{P}|\end{array}$ \\
\hline
\end{tabular}

Fonte: Elaborado pelos autores (2019)

Rossetti (2009) comenta que os preços podem ocasionar três reações nos consumidores:

a) Os preços podem se tornar obstáculos para aumentar ou diminuir a quantidade vendida;

b) aos consumidores, quanto maior o preço menor o número de consumidores dispostos a adquirir o produto;

c) Quando os preços ficam mais altos os consumidores buscam produtos com o objetivo de substituir aquele que teve seu preço alterado, reduzindo-se a quantidade demanda;

d) O consumidor está disposto a desembolsar certa quantia para a primeira unidade do produto, à medida que outras unidades estão disponíveis para compra, estas possuem menor utilidade marginal do que a primeira, então o consumidor está disposto a desembolsar menos com as unidades subsequentes à primeira.

Em função dessas reações é que se faz necessária a análise da elasticidade cruzada.

\subsection{Elasticidade cruzada}

A elasticidade cruzada da demanda mede o impacto de uma variação percentual na quantidade demandada de um bem em relação à variação percentual no preço de outro bem. Para isso, é necessário que exista alguma relação entre esses bens, caso contrário tal análise não terá sentido algum. Existem dois tipos de relação entre os produtos: substitutos ou complementares.

Substitutos são bens concorrentes no consumo, onde o consumidor pode trocar o produto desejado por outro de forma que quando há aumento no preço de um, aumenta a demanda pelo outro. Complementares são bens consumidos necessariamente em conjunto. Logo se o 
consumidor demanda um, demandará o outro também. E nesse caso, quando há queda no preço de um, aumenta a demanda pelo outro bem.

A elasticidade cruzada entre os bens X e Y é definida como:

$$
e=\frac{\Delta Q x / Q x}{\Delta P y / P y}
$$

Baye (2010) ressalta que esse conceito é muito utilizado nas estratégias de negócios. As empresas avaliam a demanda para os produtos da sua empresa em função de mudanças nos preços do produto de outras empresas.

O comportamento do consumidor em migrar suas preferências em função do aumento ou queda no preço de produtos, assim como o impacto de um produto na compra de outro está relacionado diretamente à renda do consumidor. Esse efeito será analisado no ponto a seguir.

\subsection{Elasticidade renda}

A quantidade de um bem demandado por uma pessoa depende não só do seu preço, mas também da sua renda. É natural supor que quando a renda aumenta, a quantidade demandada de um bem também aumenta.

Em função desse conceito, é possível calcular o efeito que o aumento da renda gera na quantidade demandada.

A elasticidade renda é definida como:

$$
e=\frac{\Delta Q x / Q x}{\Delta R / R}
$$

Em função do comportamento da elasticidade renda, temos dois tipos de bens:

- Bem Normal: uma elevação na renda leva a uma elevação no consumo do bem. A elasticidade é maior que zero;

- Bem Inferior: uma elevação na renda gera uma queda no consumo do bem. A elasticidade é menor que zero.

Frank (2013) chama a atenção que uma das mais importantes aplicações do conceito da elasticidade-renda é prever a composição de futuros padrões de compra. Por isso a importância de entender a classificação do bem que a empresa oferece, assim como a importância desse bem no cotidiano das pessoas. 
Diante do exposto até agora é possível tratarmos um pouco mais sobre a elasticidade preçodemanda da gasolina, a elasticidade cruzada do etanol em relação à gasolina e os impactos causados pela renda na Região Sudeste.

\section{Modelo econométrico da elasticidade preço demanda da gasolina no Sudeste}

Este capítulo tem por objetivo promover uma análise empírica acerca dos determinantes do consumo de gasolina na região Sudeste. Pretende-se avaliar como se deu a evolução do comportamento da demanda por gasolina ao longo de 30 trimestres $\left(1^{\circ}\right.$ Trim-12 até $2^{\circ}$ Trim19), a partir de seu preço, da renda e do preço do etanol. Através do método de regressão dos Mínimos Quadrados (OLS), que será explicado mais adiante, serão estimadas as elasticidades preço e renda da demanda por gasolina e a elasticidade-preço cruzada da demanda por gasolina em relação ao etanol.

\subsection{Variáveis e base de dados}

As seguintes variáveis serão utilizadas neste modelo:

a) Variável dependente:

- Consumo de gasolina em $\mathrm{m}^{3}$ (volume).

b) Variáveis independentes:

- Preço da gasolina em R $\$ /$ litro $\left(\boldsymbol{P} \boldsymbol{G}_{\text {MEDIO }}\right)$;

- Preço do etanol em R $\$$ /litro (PE

- Rendimento médio nominal efetivamente recebido em $\mathrm{R} \$(R)$.

As fontes de informação utilizadas foram: ANP para os dados de consumo trimestrais de gasolina em mil $\mathrm{m}^{3}$, para os dados de preço da gasolina e do etanol em $\mathrm{R} \$ /$ litro e IBGE para os dados de rendimento médio. Neste trabalho foi utilizado o E-Views. As variáveis apresentadas acima foram convertidas para escala logarítmica, no intuito de facilitar a interpretação dos coeficientes de cada uma delas. Assim, tais coeficientes passam a ser vistos como variações percentuais. 
Gráfico 5 - Evolução do consumo de gasolina em m3 (escala logarítmica)

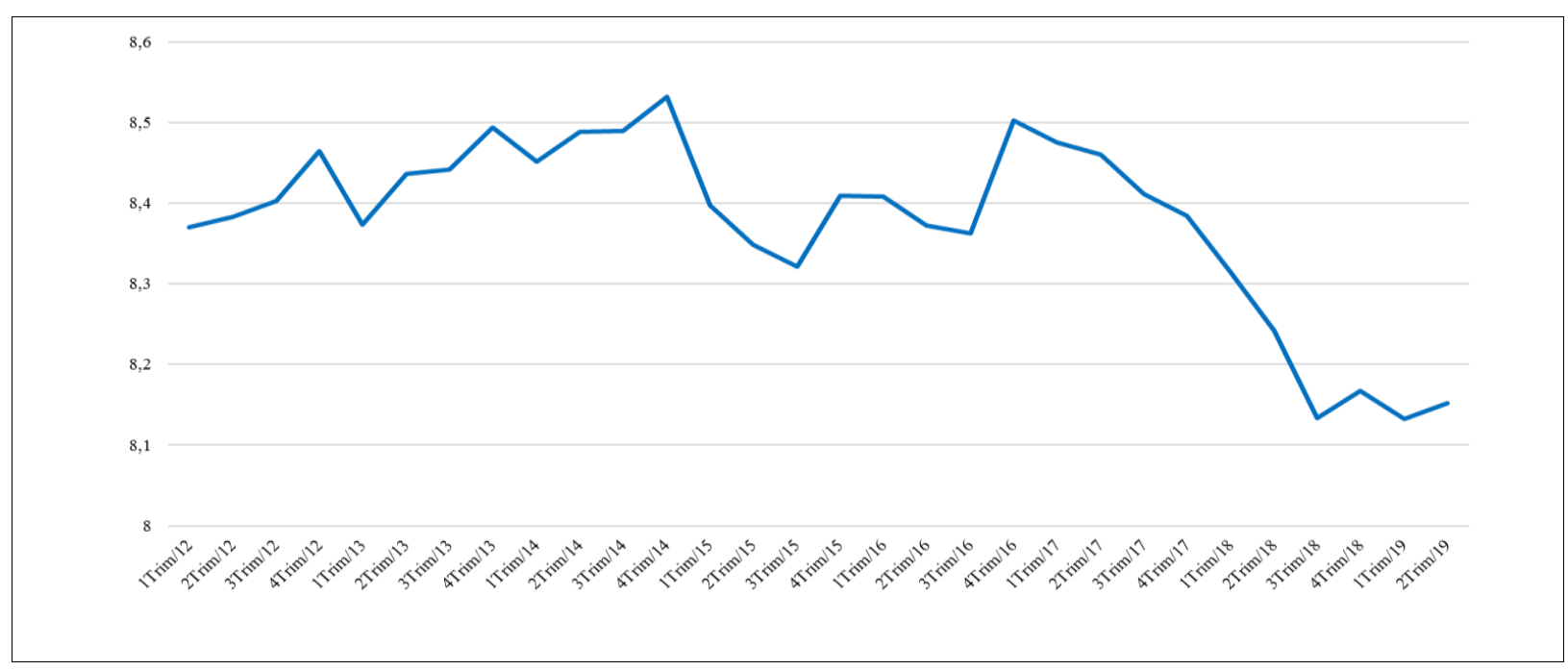

Fonte: Elaborada pelos autores (2019)

Gráfico 6 - Evolução do preço médio da gasolina em R \$/Litro (escala logarítmica)

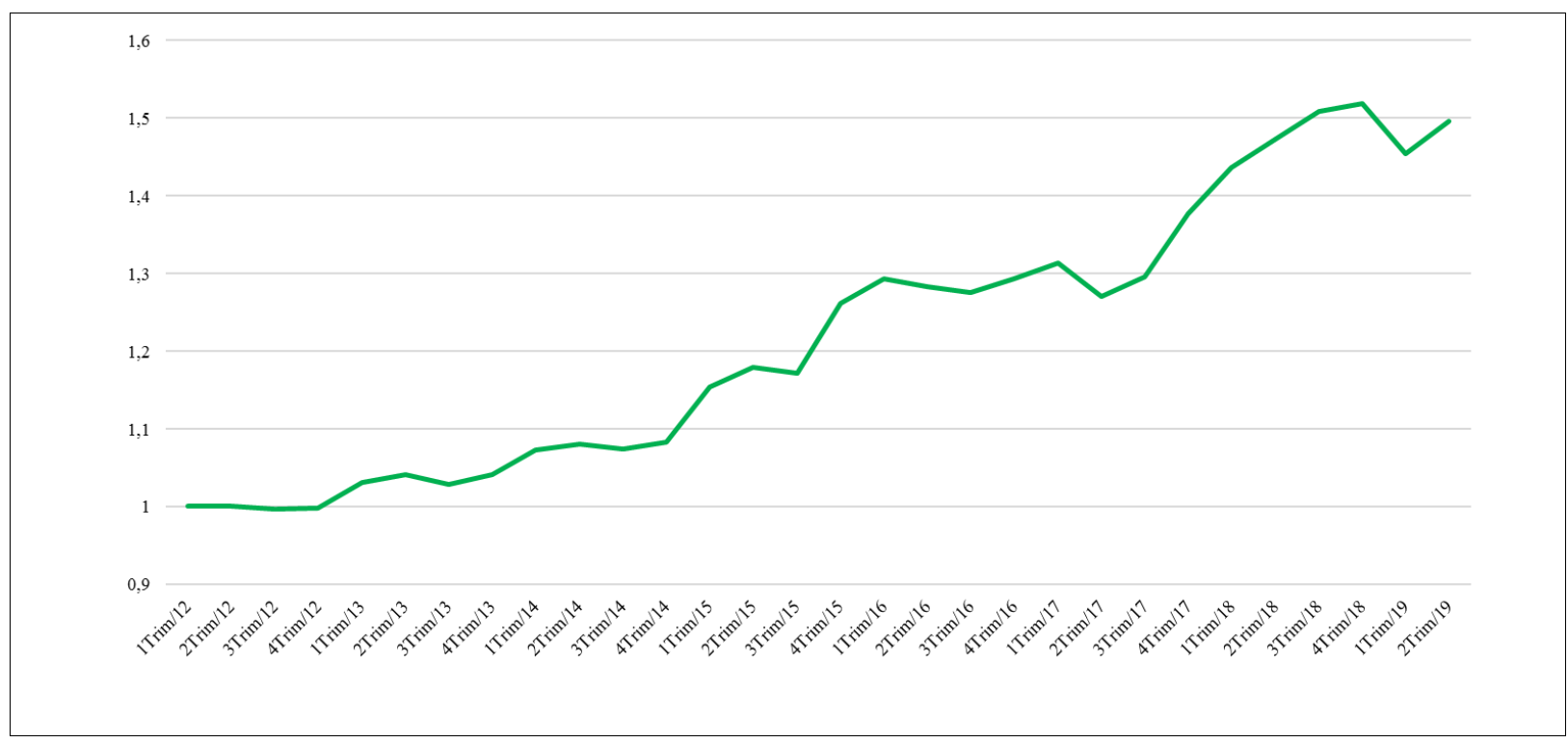

Fonte: Elaborado pelos os autores (2019) 
Gráfico 7 - Evolução do preço médio do etanol em R \$/litro (escala logarítmica)

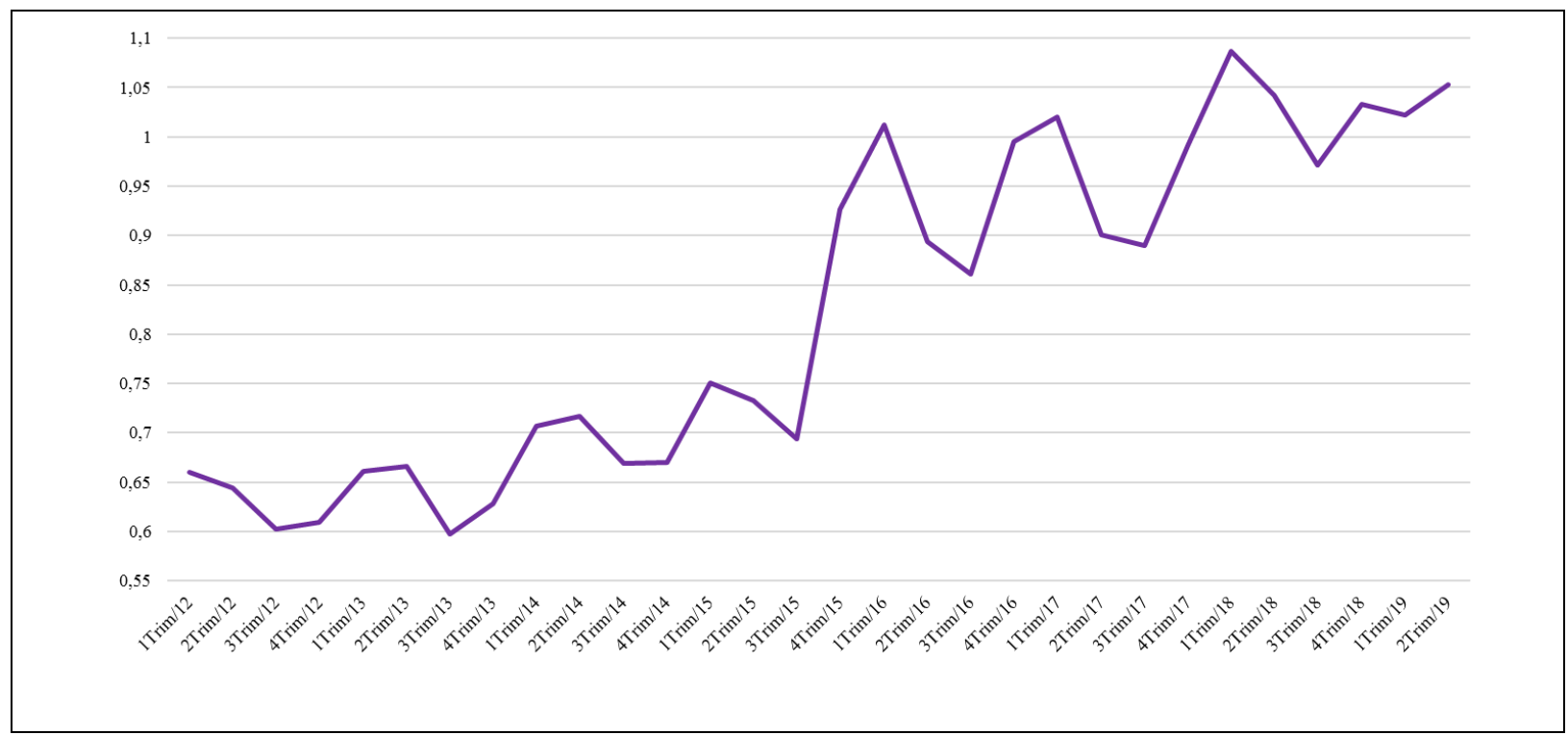

Fonte: Elaborado pelos os autores (2019)

Gráfico 8 - Evolução do rendimento médio em R \$ (escala logarítmica)

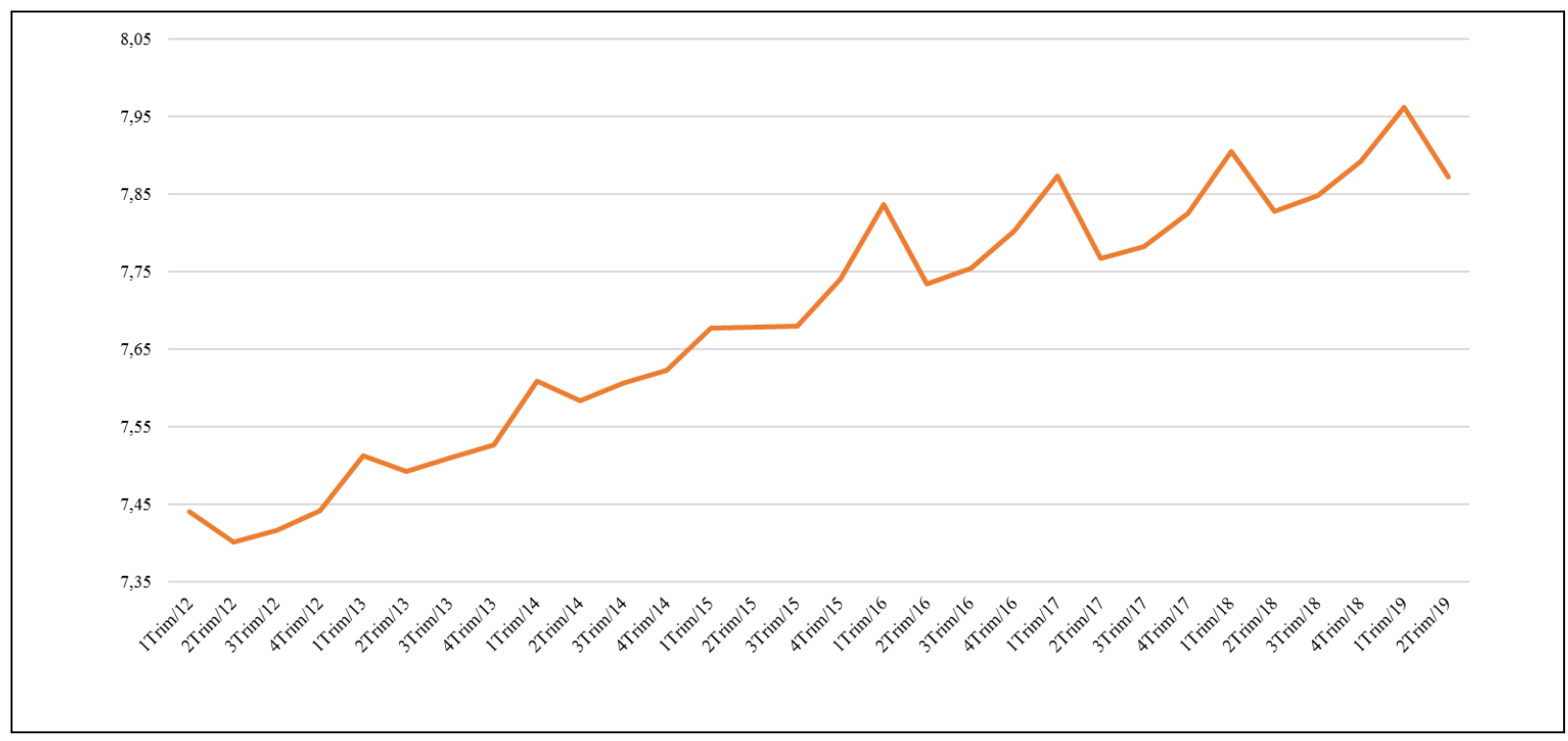

Fonte: Elaborado pelos os autores (2019)

\subsection{Estimação da função a ser utilizada}

O motivo de se usar o modelo OLS é porque, além de ser o mais utilizado, é também intuitivamente convincente e matematicamente mais simples. Gujarati (2011) nos lembra que 
o objetivo da análise de regressão não é apenas o de obter $\widehat{\beta}_{1}$ e $\widehat{\beta}_{2}$, mas o de tecer inferências relativas aos verdadeiros $\beta_{1}$ e $\beta_{2}$.

Para que o modelo OLS seja eficiente é importante testar algumas premissas:

a) Os erros possuem distribuição normal;

b) A variância do erro é constante (homocedasticidade);

c) Ausência de multicolinearidade.

A partir da realização de todas as análises descritas acima é de se esperar os seguintes resultados:

Quadro 2 - Resultado esperado do modelo

\begin{tabular}{|c|c|c|}
\hline Variáveis explicativas & Elasticidade & Sinais aguardados \\
\hline Preço da Gasolina & Elasticidade-preço da gasolina & Negativo \\
\hline Preço do Etanol & $\begin{array}{l}\text { Elasticidade-preço cruzada da } \\
\text { gasolina em relação ao etanol }\end{array}$ & Positivo \\
\hline Renda & Elasticidade-renda da gasolina & Positivo \\
\hline
\end{tabular}

Fonte: Elaborada pelos autores (2019)

Uma vez confirmados estes resultados, espera-se encontrar que a gasolina é um bem comum, ou seja, quando seu preço aumenta, a quantidade demandada diminui; é um bem normal, isto é, quando a renda do consumidor aumenta, a quantidade demandada também aumenta; e possui o etanol como bem substituto, o que significa que um aumento no preço da gasolina levaria, coeteris paribus, a um aumento no consumo de etanol.

\section{Resultados da estimação do modelo}

Antes de apresentar o modelo e verificar se os sinais esperados foram encontrados, é necessário analisar os erros e testar se eles se enquadram dentro das premissas do modelo de regressão dos mínimos quadrados. Os resultados dos testes estão na seção "anexos". Abaixo apresentaremos a análise dos resultados dos testes. 
1. Distribuição normal dos erros: O Teste de Jarque-Bera demonstrou que há distribuição normal dos erros $(7,1 \%$ de probabilidade de não rejeitar a hipótese nula ou seja, aceita a hipótese nula de que a distribuição dos erros é normal);

2. Homocedasticidade: O Teste de Heterocedasticidade demonstrou que a variância dos erros é constante (Prob F-statistic $=0,493268$ ). Sendo maior que 0,05 aceita-se a hipótese nula de que a variância dos erros é constante;

3. Ausência de Multicolinearidade: Oo Teste de Breusch-Godfrey demonstrou que não existe correlação entre os erros (Prob $F=0,3292$ ). Sendo maior que 0,05 aceita-se a hipótese nula de que não há correlação entre os erros.

Observando o modelo temos que as variáveis independentes são significativas, o modelo é consistente e está de acordo com as hipóteses para uma regressão do Mínimos Quadrados.

Figura 1 - Resultado da regressão dos mínimos quadrados

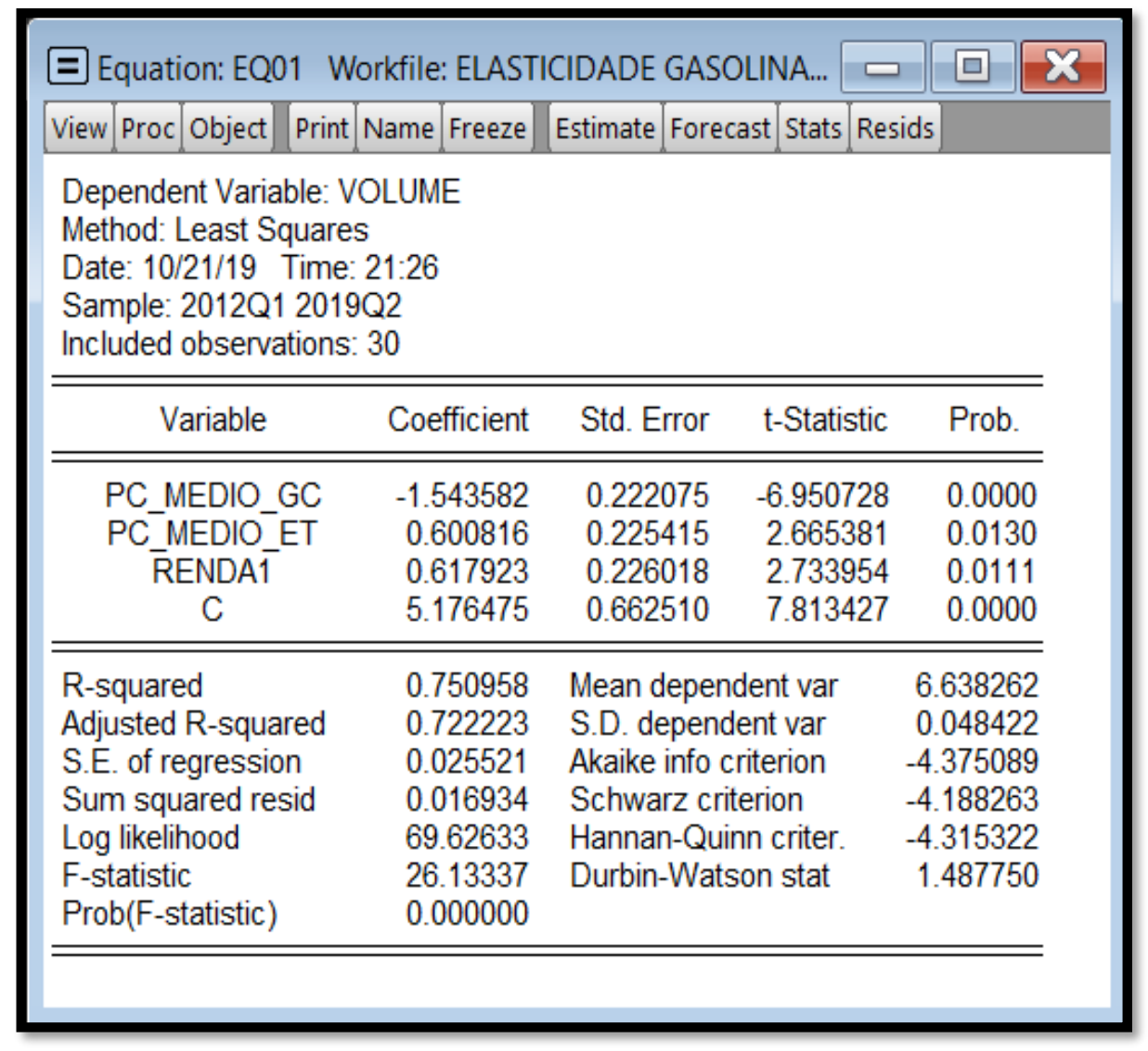

Fonte: Elaborada pelos autores

A demanda por gasolina no Sudeste é uma função linear conforme descrito abaixo:

$$
\text { VOLUME }=-1.54 P G_{M E D I O}+0.60 * P E_{M E D I O}+0.62 * R+\varepsilon
$$


Tabela 1- Resultado da elasticidade das variáveis

\begin{tabular}{lc}
\hline Elasticidade & Resultado \\
\hline Elasticidade-preço da gasolina & $-1,543582$ \\
Elasticidade-preço cruzada da gasolina em relação ao & $+0,600816$ \\
etanol & \\
Elasticidade-renda da gasolina & $+0,617923$ \\
\hline
\end{tabular}

Fonte: Elaborada pelos autores

Com base na equação de demanda de gasolina do Sudeste no período estudado é possível emitir algumas conclusões:

- Aumento de $1 \%$ no preço da gasolina reduz o consumo em 1,54\%;

- Aumento de $1 \%$ na renda reflete num aumento de $0,62 \%$ no consumo da gasolina;

- Aumento de $1 \%$ no preço do etanol faz com que o consumo da gasolina aumente em $0,6 \%$.

\section{Conclusão}

A gasolina é um dos itens mais consumidos no Brasil, principalmente na região Sudeste por conta da concentração da frota brasileira. A dependência desse produto no estilo de vida do brasileiro é tão significativa que é relevante estudar o comportamento de compra desse produto para consumidores e empresários. Portanto, é indispensável entender e conhecer a elasticidadepreço. A análise da elasticidade deve fazer parte do rol de ferramentas de gestão das organizações, conhecer o quanto seus produtos reagem a variações de preço e renda é um fator que não deve ser menosprezado. Ao avaliar a elasticidade da demanda por gasolina percebe-se que se trata de um bem com baixa elasticidade, e que, apesar de toda mudança ocorrida nas últimas décadas - a entrada do etanol no mercado brasileiro e aumento dos carros flexfuel, se mostrou um forte produto alternativo - a gasolina continua a ser uma das principais fontes de combustível. A análise dos dados revela que a demanda preço e demanda cruzada da gasolina é baixa e variações no preço tem baixo impacto na quantidade demandada. Em relação à renda percebe-se que quanto maior a renda, maior o consumo de gasolina.

Logo, mesmo com todas as instabilidades no cenário internacional nos últimos anos, a existência de um produto substituto (etanol) e proliferação dos carros flexfuel, a gasolina continua sendo um produto representativo na cesta de consumo do brasileiro. 


\section{REFERÊNCIAS}

BAYE, Michel. Economia de Empresas e Estratégias de Negócios, 6ª Ed., São PAULO, AMGH Editora, 2010. P. 85

BUAINAIN, A. M.; GARCIA, J. R. Contextos locais ou regionais: importância para a viabilidade econômica dos pequenos produto-res. In: SANTOS, M. de M.; PINHEIRO, B.; SANTANA, C.; GUEDES, A. C.; BARBOSA, M. M. T. L.; SETUBAL, J. H.; PINHEIRO, B.; SANTANA, C. (Org.). A pequena produção rural e as tendências do desenvolvimento agrário brasileiro: ganhar tempo é possível?, Brasília: CGEE, 2013.

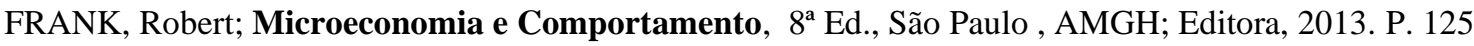

GUJARATI, D., PORTER, D. (2011) Econometria Básica, 5ª ed., São Paulo, AMGH Editora Ltda. P.78

LIMA, R. O. C.; Processo de Formação de Preços, Curitiba, IESDE, 2009.

MELLO, André de Souza; SAMPAIO, Yony de Sá. Impactos dos Preços da Gasolina e do Etanol sobre a Demanda de Etanol no Brasil, Revista de Economia Contemporânea, UFPE, Pernambuco, 2014.

NAPPO, Marcio; A Demanda por gasolina no Brasil: uma avaliação de suas elasticidades após a introdução dos carros bicombustível. Dissertação (Mestrado) - Escola de Economia de São Paulo da Fundação Getúlio Vargas, São Paulo, 2007.

ORELLANO, Veronica Fernanda; SOUZA, Alberto de Nes and AZEVEDO, Paulo Furquim. Elasticidade-preço da demanda por etanol no Brasil: como renda e preços relativos explicam a diferenças entre estados. Revista de Economia e Sociologia, Brasília, vol.51, p1., Epub Oct/Dez, 2013.

PINTO Jr, H. Q.; Comércio externo de petróleo e derivados: a estratégia pós-choque. In: Congresso Brasileiro de Planejamento Energético I, 1989, Campinas. Anais. Rio de Janeiro. COPPE/UFRJ, 1989. pp.37-53.

PINDYCK, R. S.; RUBINFELD, D. L. Microeconomia: teoria microeconômica. São Paulo: Makron Books, 1994, P. 122

ROSSETI, J. P.. Introdução à economia. São Paulo: Atlas, 2009, P. 348

SAMPAIO, L.; Microeconomia Esquematizado. São Paulo, Editora Saraiva, SP, 2011.

SANTANNA, Eduardo Pimentel; BASTOS, Cesar Albuquerque, Elasticidade da Demanda por Gasolina no Brasil e o Uso de Tecnologia Flex Fuel no Período 2001 - 2012.

tps://www.anpec.org.br/encontro/2014/submissao/files_I/i8-acfa1a7b20d29026ee0ee9ec9b04e17f.pdf.> acesso em: 30 out.2019

UCZAI, P. Energias Renováveis riqueza sustentável ao alcance da sociedade. CÂMARA DOS DEPUTADOS, Brasília-DF, n.10, p.1-273, 2012.

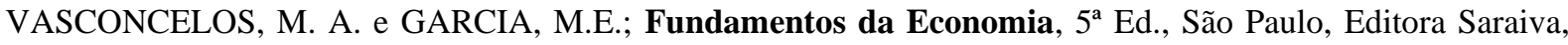
2014. 


\section{Anexos:}

Figura 2 - Teste de Jarque-Bera

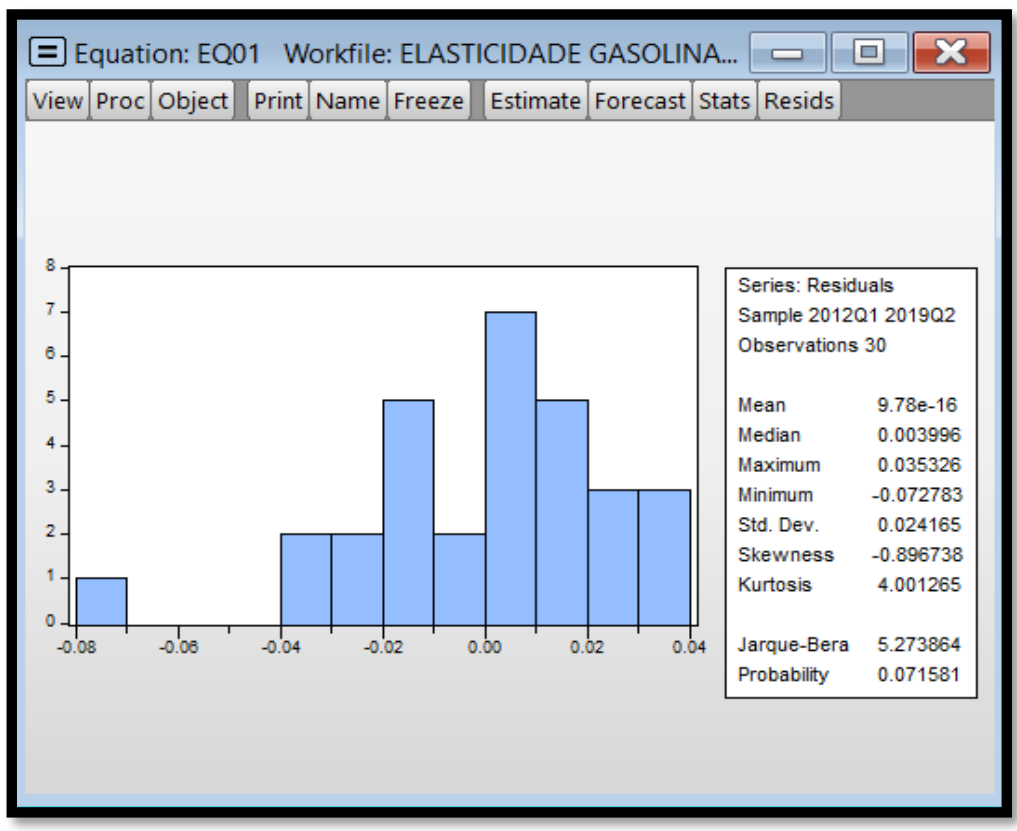

Fonte: Elaborada pelos autores

Figura 2 - Teste de Heterocidasticidade

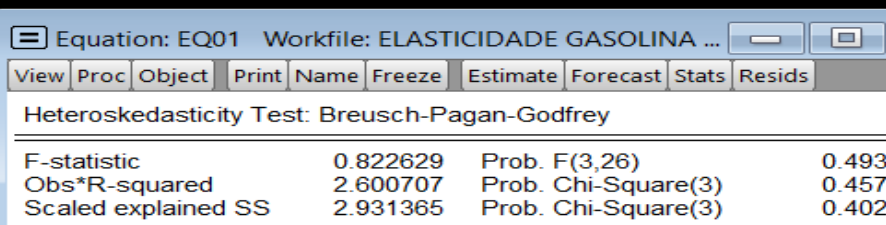

Test Equation

Dependent Variable: RESID ${ }^{\wedge}$

Method: Least Squares

Date: $10 / 21 / 19$ Time: 21:41

Sample: 2012Q1 2019Q2

Included observations: 30

\begin{tabular}{crrrr}
\hline \hline Variable & Coefficient & Std. Error & t-Statistic & Prob. \\
\hline \hline C & -0.035496 & 0.026060 & -1.362112 & 0.1848 \\
PC_MEDIO_GC & -0.005130 & 0.008735 & -0.587256 & 0.5621 \\
PC_MEDIO_ET & -0.004007 & 0.008867 & -0.451905 & 0.6551 \\
RENDA1 & 0.012043 & 0.008890 & 1.354656 & 0.1872 \\
\hline \hline R-squared & 0.086690 & Mean dependent var & 0.000564 \\
Adjusted R-squared & -0.018692 & S.D. dependent var & 0.000995 \\
S.E. of regression & 0.001004 & Akaike info criterion & -10.84637 \\
Sum squared resid & $2.62 E-05$ & Schwarz criterion & -10.65954 \\
Log likelihood & 166.6955 & Hannan-Quinn criter. & -10.78660 \\
F-statistic & 0.822629 & Durbin-Watson stat & 2.043686 \\
Prob(F-statistic) & 0.493268 & & & \\
\hline
\end{tabular}

Fonte Elaborada pelos autores 
Figura 3 - Teste de Breusch-Godfrey

\begin{tabular}{|c|c|c|c|c|c|}
\hline \multicolumn{6}{|c|}{$\Xi$ Equation: EQ01 Workfile: ELASTICIDADE GASOLINA SU... $\square \square$} \\
\hline \begin{tabular}{|l|l|l|l|l|l|} 
View & Proc & Object & Print \\
\end{tabular} & Name Freeze & Estimate Forecas & st $[$ Stats $\operatorname{Re}$ & Resids & \\
\hline \multicolumn{6}{|c|}{ Breusch-Godfrey Serial Correlation LM Test: } \\
\hline $\begin{array}{l}\text { F-statistic } \\
\text { Obs*R-squared }\end{array}$ & $\begin{array}{l}1.164196 \\
2.653095\end{array}$ & $\begin{array}{l}\text { Prob. F(2,24) } \\
\text { Prob. Chi-Squ }\end{array}$ & uare(2) & & $\begin{array}{l}0.3292 \\
0.2654\end{array}$ \\
\hline \multicolumn{6}{|c|}{$\begin{array}{l}\text { Test Equation: } \\
\text { Dependent Variable: RESID } \\
\text { Method: Least Squares } \\
\text { Date: } 10 / 21 / 19 \text { Time: } 21: 42 \\
\text { Sample: } 2012 \mathrm{Q} 12019 \mathrm{2} 2 \\
\text { Included observations: } 30 \\
\text { Presample missing value lagg }\end{array}$} \\
\hline Variable & Coefficient & Std. Error & t-Statistic & & Prob. \\
\hline $\begin{array}{l}\text { PC_MEDIO_GC } \\
\text { PC_MEDIO_ET } \\
\text { RENDA1 } \\
\text { C } \\
\text { RESID(-1) } \\
\text { RESID(-2) }\end{array}$ & $\begin{array}{r}0.099436 \\
0.022474 \\
-0.167991 \\
0.499281 \\
0.264042 \\
0.244397\end{array}$ & $\begin{array}{l}0.234570 \\
0.227232 \\
0.259827 \\
0.761539 \\
0.230761 \\
0.263669\end{array}$ & $\begin{array}{r}0.42390 € \\
0.098903 \\
-0.646547 \\
0.65562 \\
1.14422 \\
0.92690 £\end{array}$ & & $\begin{array}{l}0.6754 \\
0.9220 \\
0.5241 \\
0.5183 \\
0.2638 \\
0.3632\end{array}$ \\
\hline $\begin{array}{l}\text { R-squared } \\
\text { Adjusted R-squared } \\
\text { S.E. of regression } \\
\text { Sum squared resid } \\
\text { Log likelihood } \\
\text { F-statistic } \\
\text { Prob(F-statistic) }\end{array}$ & $\begin{array}{r}0.088437 \\
-0.101473 \\
0.025361 \\
0.015436 \\
71.01524 \\
0.465678 \\
0.797875\end{array}$ & \multicolumn{2}{|c|}{$\begin{array}{l}\text { Mean dependent var } \\
\text { S.D. dependent var } \\
\text { Akaike info criterion } \\
\text { Schwarz criterion } \\
\text { Hannan-Quinn criter. } \\
\text { Durbin-Watson stat }\end{array}$} & & $\begin{array}{l}78 \mathrm{E}-16 \\
024165 \\
334350 \\
054110 \\
244699 \\
699899\end{array}$ \\
\hline
\end{tabular}

